\title{
Adeno-Associated Virus Type 2-Mediated Gene Transfer: Role of Cellular FKBP52 Protein in Transgene Expression
}

\author{
KEYUN QING, ${ }^{1,2,3}$ JONATHAN HANSEN, ${ }^{1,2,3}$ KIRSTEN A. WEIGEL-KELLEY, ${ }^{1,2,3}$ MENGQUN TAN, ${ }^{1,2,3}$ \\ SHANGZHEN ZHOU, ${ }^{4}$ AND ARUN SRIVASTAVA ${ }^{1,2,3,5 *}$ \\ Department of Microbiology \& Immunology, ${ }^{1}$ Walther Oncology Center, ${ }^{2}$ Walther Cancer Institute, ${ }^{3}$ and Division of \\ Hematology/Oncology, ${ }^{5}$ Department of Medicine, Indiana University School of Medicine, \\ Indianapolis, Indiana 46202, and Avigen, Inc., Alameda, California $94501^{4}$
}

Received 27 February 2001/Accepted 22 June 2001

\begin{abstract}
Although adeno-associated virus type 2 (AAV) has gained attention as a potentially useful vector for human gene therapy, the transduction efficiencies of AAV vectors vary greatly in different cells and tissues in vitro and in vivo. We have documented that a cellular tyrosine phosphoprotein, designated the single-stranded Dsequence-binding protein (ssD-BP), plays a crucial role in AAV-mediated transgene expression (K. Y. Qing, X.-S. Wang, D. M. Kube, S. Ponnazhagan, A. Bajpai, and A. Srivastava, Proc. Natl. Acad. Sci. USA 94:1087910884, 1997). We have documented a strong correlation between the phosphorylation state of ssD-BP and AAV transduction efficiency in vitro as well as in vivo (K. Y. Qing, B. Khuntrirat, C. Mah, D. M. Kube, X.-S. Wang, S. Ponnazhagan, S. Z. Zhou, V. J. Dwarki, M. C. Yoder, and A. Srivastava, J. Virol. 72:1593-1599, 1998). We have also established that the ssD-BP is phosphorylated by epidermal growth factor receptor protein tyrosine kinase and that the tyrosine-phosphorylated form, but not the dephosphorylated form, of ssD-BP prevents AAV second-strand DNA synthesis and, consequently, results in a significant inhibition of AAV-mediated transgene expression (C. Mah, K. Y. Qing, B. Khuntrirat, S. Ponnazhagan, X.-S. Wang, D. M. Kube, M. C. Yoder, and A. Srivastava, J. Virol. 72:9835-9841, 1998). Here, we report that a partial amino acid sequence of ssD-BP purified from HeLa cells is identical to a portion of a cellular protein that binds the immunosuppressant drug FK506, termed the FK506-binding protein 52 (FKBP52). FKBP52 was purified by using a prokaryotic expression plasmid containing the human cDNA. The purified protein could be phosphorylated at both tyrosine and serine or threonine residues, and only the phosphorylated forms of FKBP52 were shown to interact with the AAV single-stranded D-sequence probe. Furthermore, in in vitro DNA replication assays, tyrosine-phosphorylated FKBP52 inhibited AAV second-strand DNA synthesis by greater than $\mathbf{9 0 \%}$. Serine- or threoninephosphorylated FKBP52 caused $\approx 40 \%$ inhibition, whereas dephosphorylated FKBP52 had no effect on AAV second-strand DNA synthesis. Deliberate overexpression of FKBP52 effectively reduced the extent of tyrosine phosphorylation of the protein, resulting in a significant increase in AAV-mediated transgene expression in human and murine cell lines. These studies corroborate the idea that the phosphorylation status of the cellular FKBP52 protein correlates strongly with AAV transduction efficiency, which may have important implications for the optimal use of AAV vectors in human gene therapy.
\end{abstract}

Adeno-associated virus type 2 (AAV) is a small, nonpathogenic, single-stranded DNA-containing virus which requires coinfection with a helper virus, usually adenovirus, for its optimal replication $(1,31)$. In the absence of coinfection with the helper virus, the wild-type AAV establishes a latent infection in which the viral genome integrates into human chromosomal DNA in a site-specific manner $(22,23,45)$. The nonpathogenic nature of AAV coupled with the remarkable site specificity of integration prompted the development of recombinant AAV vectors for gene transfer and gene therapy. Although recombinant AAV genomes do not appear to integrate site specifically, AAV vectors have been successfully used for gene delivery to a wide variety of cells and tissues in vitro and in vivo (2, $3,11,12,16-19,21,32-36,47,48,51,55,57)$, as well as in phase I clinical trials for gene therapy of cystic fibrosis and hemophilia B $(11,18)$. However, the transduction efficiencies

* Corresponding author. Mailing address: Department of Microbiology \& Immunology, Indiana University School of Medicine, Medical Science Building Room 257, 635 Barnhill Dr., Indianapolis, IN 462025120. Phone: (317) 274-2194. Fax: (317) 274-4090. E-mail: asrivast @iupui.edu. of AAV vectors vary greatly in different cell types. Studies from two independent laboratories have suggested that following infection, the viral second-strand DNA synthesis is a ratelimiting step in efficient transduction by AAV vectors $(8,9)$. We have documented that a host cell protein, designated the single-stranded D-sequence binding protein (ssD-BP), interacts specifically and preferentially with the $\mathrm{D}$ sequence within the inverted terminal repeat (ITR) at the $3^{\prime}$ end of the AAV genome and, in its tyrosine-phosphorylated form, prevents viral second-strand DNA synthesis, resulting in inhibition of AAV-mediated transgene expression. ssD-BP is phosphorylated at tyrosine residues by the epidermal growth factor receptor protein tyrosine kinase (EGFR-PTK), and the phosphorylation state of ssD-BP correlates with the AAV transduction efficiency in established and primary human cells in vitro and in murine tissues in vivo $(25,26,40,42,52,53)$. Despite the crucial role that ssD-BP plays in AAV-mediated transgene expression, its identity has remained unknown.

In this report, we present data on the purification and characterization of ssD-BP. The partial amino acid sequence of this protein, purified to homogeneity from HeLa cells, revealed $100 \%$ homology to a cellular protein, termed FK506-binding 
protein 52 (FKBP52), which binds the immunosuppressant drug FK506. This 52-kDa protein, which has also been shown to be a chaperone protein, is ubiquitous, is phosphorylated, and localizes predominantly to the nucleus, properties that are shared with ssD-BP. The purified recombinant human FKBP52 protein could be phosphorylated by both casein kinase II (CK II) and EGFR-PTK. The purified protein was also shown to interact with the AAV single-stranded D-sequence probe by electrophoretic mobility shift assays (EMSA). Furthermore, in in vitro DNA replication assays, EGFR-PTKphosphorylated FKBP52 inhibited AAV second-strand DNA synthesis by greater than $90 \%$. CK II-phosphorylated FKBP52 caused $\approx 40 \%$ inhibition, whereas unphosphorylated FKBP52 had no effect on AAV second-strand DNA synthesis. Deliberate overexpression of FKBP52 led to a reduction in tyrosine phosphorylation of the protein, which resulted in a significant increase in AAV-mediated transgene expression in human and murine cell lines. These studies corroborate the idea that the cellular FKBP52 protein is a crucial determinant of AAV transduction efficiency, which in turn may have important implications for the optimal use of AAV vectors in human gene therapy.

\section{MATERIALS AND METHODS}

Cells, viruses, plasmids, and antibodies. The human cervical carcinoma cell line HeLa, the adenovirus-transformed human embryonic kidney cell line 293, and the murine fibroblast cell line NIH 3T3 were obtained from the American Type Culture Collection (Manassas, Va.) and maintained as monolayer cultures in Iscove's modified Dulbecco's medium (IMDM) supplemented with $10 \%$ fetal bovine serum and $1 \%$ (by volume) $100 \times$ stock solution of antibiotics $(10,000 \mathrm{U}$ of penicillin plus $10,000 \mu \mathrm{g}$ of streptomycin). Human AAV and adenovirus type 2 stocks were kindly supplied by Kenneth I. Berns (University of Florida, Gainesville) and Kenneth H. Fife (Indiana University School of Medicine, Indianapolis), respectively. The recombinant plasmids $\mathrm{pQE}-30$ and $\mathrm{pCMV} \beta$ were obtained from Qiagen (Valencia, Calif.) and Clontech (Palo Alto, Calif.), respectively. Antibodies specific for human FKBP52 (goat polyclonal immunoglobulin G $[\operatorname{IgG}]$ ) and human $\beta_{1}$ integrin (mouse monoclonal $\operatorname{IgG} 1$ ) were purchased from Santa Cruz Biotechnology (Santa Cruz, Calif.) and Chemicon Corp. (Temecula, Calif.), respectively.

Preparation of WCEs. Whole-cell extracts (WCEs) from HeLa, 293, and NIH 3 T3 cells were prepared according to the method described by Muller (30). The total protein concentration was determined by the Bio-Rad Laboratories (Hercules, Calif.) protein assay kit, and the extracts were frozen in liquid $\mathrm{N}_{2}$ and stored at $-70^{\circ} \mathrm{C}$.

EMSA were performed as described previously $(42,53)$. Briefly, DNA-binding reactions were performed in a volume of $20 \mu \mathrm{l}$ with $2 \mu \mathrm{g}$ of poly(dI-dC), $2 \mu \mathrm{g}$ of bovine serum albumin, and $12 \%$ glycerol in HEPES buffer ( $\mathrm{pH} 7.9)$. Ten micrograms of proteins from each WCE were preincubated for $10 \mathrm{~min}$ at $25^{\circ} \mathrm{C}$ followed by the addition of $10,000 \mathrm{cpm}$ of ${ }^{32} \mathrm{P}$-labeled $\mathrm{D}(-)$-sequence synthetic oligonucleotide (5'-AGGAACCCCTAGTGATGGAG-3') to the reaction mixture. The binding reaction was allowed to proceed for $30 \mathrm{~min}$ at $25^{\circ} \mathrm{C}$. In some experiments, specific (FKBP52) and nonspecific ( $\beta_{1}$ integrin) antibodies were also used in supershift assays as described previously $(15,20)$ with the following modifications. Briefly, the reaction mixture was incubated with $2 \mu \mathrm{g}$ of antibody on ice for $1 \mathrm{~h}$ and then at $25^{\circ} \mathrm{C}$ for $15 \mathrm{~min}$. In some experiments, WCEs were also immunoprecipitated with anti-FKBP52 antibody, and supernatants and resuspended pellets were used in EMSA as previously described (44). Bound complexes were separated from the unbound probe on low-ionic-strength $4 \%$ polyacrylamide gels using Tris-glycine-EDTA buffer $(\mathrm{pH} 8.5)$ containing $50 \mathrm{mM}$ Tris- $\mathrm{HCl}, 380 \mathrm{mM}$ glycine, and $2 \mathrm{mM}$ EDTA. Following electrophoresis, the gel was dried in vacuo and autoradiographed with Kodak X-Omat film at $-70^{\circ} \mathrm{C}$.

Purification of ssD-BP. WCE was prepared as described above from $\approx 2.6 \times$ $10^{10} \mathrm{HeLa}$ cells purchased from the National Cell Culture Center (Washington, D.C.). All steps were carried out at $4^{\circ} \mathrm{C}$. The WCE was subjected to ultrafiltration on Centricon columns (Amicon, Beverly, Mass.) to remove proteins with masses of less than $30 \mathrm{kDa}$. The rest of the WCE was fractionated on a Sephacryl S-200 HR column (Sigma, St. Louis, Mo.). The column bed volume was $100 \mathrm{ml}$, which was equilibrated with 2 bed volumes of buffer A $(20 \mathrm{mM}$ Tris- $\mathrm{HCl}[\mathrm{pH}$ 7.5], $50 \mathrm{mM} \mathrm{NaCl}, 1 \mathrm{mM} \mathrm{MgCl} 2,0.5 \%$ NP-40, $0.5 \mathrm{mM}$ phenylmethylsulfonyl fluoride, $0.5 \mathrm{mM}$ dithiothreitol). After the sample was loaded, the column was washed and eluted with 2 bed volumes of buffer A. Four-milliliter fractions were collected, and the protein concentration was determined. All fractions containing proteins were used in EMSA with the AAV D-sequence probe as described above. All positive fractions were pooled and fractionated by anion-exchange chromatography on a DE-52 column. The column bed volume was $50 \mathrm{ml}$, which was equilibrated with buffer A. After the sample was loaded, the column was washed with 1 bed volume of buffer A followed by elution with a continuous $\mathrm{NaCl}$ concentration gradient $(50$ to $500 \mathrm{mM})$. Two-milliliter fractions were collected, and the protein concentration was determined. All fractions containing proteins were dialyzed overnight against buffer A, followed by EMSA. All positive fractions were pooled and subjected to chromatography using a nonspecific ssDNA-agarose column (Life Technologies, Rockville, Md.). The column bed volume was $2 \mathrm{ml}$, which was equilibrated with buffer A. After the sample was loaded, the column was washed with 1 bed volume of buffer A followed by elution with a stepwise $\mathrm{NaCl}$ concentration gradient (100 $\mathrm{mM}$ to $1 \mathrm{M})$. Twomilliliter fractions were collected and dialyzed overnight against buffer A, followed by EMSA. All positive eluates containing the ssD-BP were incubated with the ssD sequence-ligated streptavidin magnetic particles (Boehringer Mannheim, Indianapolis, Ind.) according to the instructions provided by the vendor. The bound ssD-BP was eluted from the particles and electrophoresed on preparative sodium dodecyl sulfate (SDS) $-10 \%$ polyacrylamide gels. A single protein band with a mass of $\approx 52 \mathrm{kDa}$ was excised and shipped to the Harvard Microchemistry Facility, Harvard University (Cambridge, Mass.) for mass spectrometry and protein microsequencing analyses.

Expression and purification of the recombinant human FKBP52 protein from Escherichia coli. A prokaryotic expression plasmid containing the human FKBP52 gene was generated by PCR amplification from a HeLa cell Marathonready cDNA library (Clontech) with the following primer pair: $5^{\prime}$ primer, GAT GACAGCCGAGGAGATGAAGGCGACCGA, and 3' primer, GTTATGCTT CTGTCTCCACCTGAGACTGGC. The sequence of the PCR product was confirmed by sequencing and then inserted into the pQE-30 prokaryotic expression vector. The recombinant FKBP52 protein was produced and purified using the His tag purification system and $\mathrm{Ni}^{2+}$ affinity chromatography (Qiagen) according to the instructions provided by the vendor. A eukaryotic expression plasmid containing the human FKBP52 cDNA gene under the control of the cytomegalovirus (CMV) immediate-early promoter was also constructed by standard methods as described previously (41).

In vitro phosphorylation assays. In vitro phosphorylation by EGFR-PTK was carried out as previously described by Weber et al. (54) and Cybulsky et al. (4) with the following modifications. The complete reaction mixture contained $1 \mu \mathrm{g}$ of the purified FKBP52 protein, $20 \mathrm{mM}$ HEPES, $4 \mathrm{mM} \mathrm{MgCl} 2,10 \mathrm{mM} \mathrm{MnCl}$, $50 \mathrm{mM} \mathrm{NaOV}, 200 \mu \mathrm{M}$ ATP, $10 \mu \mathrm{Ci}(0.37 \mathrm{mBq})$ of $\left[\gamma^{3}{ }^{32} \mathrm{P}\right] \mathrm{ATP}$, and $1 \mathrm{U}(15,000$ $\mathrm{U} / \mathrm{mg}$ ) of purified EGFR-PTK (CalBiochem, La Jolla, Calif.) with all appropriate controls. In vitro phosphorylation by CK II (CalBiochem) was carried out as previously described by McElhinny et al. (28) and Russo et al. (43). Briefly, the complete reaction mixture contained $1 \mu \mathrm{g}$ of the FKBP52 protein expressed in and purified from bacterial cultures, $20 \mathrm{mM}$ Tris- $\mathrm{HCl}, 50 \mathrm{mM} \mathrm{KCl}, 10 \mathrm{mM}$ $\mathrm{MgCl}_{2}, 50 \mathrm{mM} \mathrm{NaOV}, 200 \mu \mathrm{M}$ ATP, $10 \mu \mathrm{Ci}(0.37 \mathrm{mBq})$ of $\left[\gamma^{-}{ }^{32} \mathrm{P}\right] \mathrm{ATP}$, and 100 $\mathrm{U}(300,000 \mathrm{U} / \mathrm{mg})$ of CK II. The reaction mixtures were incubated at $30^{\circ} \mathrm{C}$ for $1 \mathrm{~h}$ and electrophoresed on SDS-10\% polyacrylamide gels. The gels were dried in vacuo followed by autoradiography using Kodak X-Omat film at $-70^{\circ} \mathrm{C}$. In some experiments, in vitro phosphorylation assays with EGFR-PTK and CK II were also carried out without the addition of $\left[\gamma_{-}{ }^{32} \mathrm{P}\right] \mathrm{ATP}$. The tyrosine- and serine- or threonine-phosphorylated FKBP52 proteins were then used in EMSA with the radiolabeled $\mathrm{D}(-)$ probe as described above and in in vitro DNA replication assays as described below.

In vitro DNA replication assays. The appropriate AAV DNA substrate containing the $3^{\prime}$ hairpin structure was prepared and labeled with $\left[\gamma^{-}{ }^{32} \mathrm{P}\right] \mathrm{ATP}(3,000$ $\mathrm{Ci} / \mathrm{mmol}$ ) by using $\mathrm{T} 4$ polynucleotide kinase as described previously (44). To assess the effect of ssD-BP on AAV DNA replication (second-strand DNA synthesis), $20 \mathrm{ng}$ of the unphosphorylated, EGFR-PTK-phosphorylated, or CK II-phosphorylated form of the purified FKBP52 protein was added to the endlabeled $3^{\prime}$-hairpin ITR and all four unlabeled deoxynucleoside triphosphates and incubated for $15 \mathrm{~min}$ at $25^{\circ} \mathrm{C}$ prior to adding the Klenow enzyme. After the Klenow enzyme was added, the reaction mixtures were incubated at $37^{\circ} \mathrm{C}$ for 30 min and then electrophoresed on $6 \%$ polyacrylamide gels. The gels were dried and autoradiographed at $-70^{\circ} \mathrm{C}$ as described above.

Western blot analyses. To determine the levels of human FKBP52 in transfected cell lines, approximately $2 \times 10^{6}$ cells were seeded in culture dishes, and $24 \mathrm{~h}$ later, WCEs were prepared by an SDS lysis procedure described elsewhere 


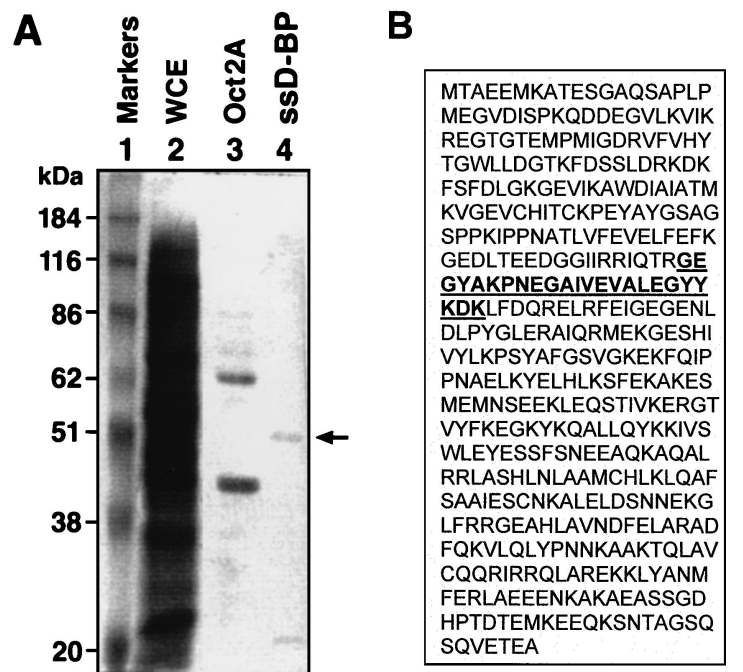

FIG. 1. (A) Purification of ssD-BP from HeLa cells. SDS-polyacrylamide gel electrophoretic pattern of purified ssD-BP. Lane 1, protein molecular size markers; lane 2, WCE of HeLa S3 cells $(20 \mu \mathrm{g}$ of total protein); lane 3, Oct2A factor, included as a positive control, purified according to the standard protocol using the protein purification kit supplied by the vendor (Boehringer Mannheim); lane 4, purified ssD-BP. The arrow indicates the $\approx 52-\mathrm{kDa}$ ssD-BP. (B) Deduced amino acid sequence of the human FKBP52 protein. The boldface underlined amino acids represent the identified homology between ssD-BP and FKBP52 (GenBank accession no. M88279).

(10). Total protein concentrations were determined using the Bio-Rad protein assay kit, and $30 \mu \mathrm{g}$ of protein was separated by SDS-polyacrylamide gel electrophoresis on a $10 \%$ polyacrylamide gel. After transfer to an Immobilon-P membrane (Millipore, Bedford, Mass.), the membrane was blocked for $1 \mathrm{~h}$ at $25^{\circ} \mathrm{C}$ with $1 \times$ Tris-buffered saline (TBS; $20 \mathrm{mM}$ Tris- $\mathrm{HCl}, \mathrm{pH} 7.5,150 \mathrm{mM}$ $\mathrm{NaCl}$ ), $0.05 \%$ Tween 20 , and $5 \%$ nonfat dry milk (TBST-milk), incubated with a 1:200 dilution of anti-FKBP52 antibody in TBST-milk for $1 \mathrm{~h}$ at $25^{\circ} \mathrm{C}$, and then washed three times in TBST. Following incubation with a 1:2,000 dilution of horseradish peroxidase-coupled anti-goat IgG antibody in TBST-milk for $1 \mathrm{~h}$ at $25^{\circ} \mathrm{C}$, the membrane was washed three times in TBST, and protein bands were visualized with the ECL-Plus chemiluminescence detection kit (Amersham, Little Chalfont, England) according to the instructions provided by the manufacturer.

Recombinant AAV-mediated transduction assays. Approximately $10^{5}$ cells per well were plated in a 12-well plate. Twelve hours later, the cells were washed once with IMDM and then infected at $37^{\circ} \mathrm{C}$ for $2 \mathrm{~h}$ with $5 \times 10^{3}$ particles of a recombinant AAV vector containing the $\beta$-galactosidase (lac $Z$ ) reporter gene driven by the CMV immediate-early promoter (vCMVp-lacZ) per cell. The cells were then incubated with complete IMDM containing $10 \%$ fetal bovine serum and $1 \%$ antibiotics for $48 \mathrm{~h}$. The $\beta$-galactosidase activity was measured by the Galacto-Light Plus chemiluminescence reporter assay (Tropics, Inc., Bedford, Mass.) according to the manufacturer's instructions. The data were expressed as relative light units per microgram of total protein and were within the linear range of the assay.

\section{RESULTS}

sSD-BP is a cellular chaperone protein, FKBP52, an immunophilin. We purified ssD-BP to homogeneity from HeLa cells as described in Materials and Methods. A small fraction of the protein was electrophoresed on an SDS-10\% polyacrylamide gel followed by staining with Coomassie blue (Fig. 1A, lane 4). As can be seen, a single protein band with a mass of $\approx 52 \mathrm{kDa}$ was obtained which interacted with the single-stranded AAV $\mathrm{D}(-)$ sequence probe in EMSA. When this protein was excised from preparative gels and subjected to protein microse- quencing, the amino acid sequence of the largest peptide, containing 24 amino acids, revealed 100\% homology to a cellular protein, FKBP52, that binds the immunosuppressant drug FK506 (Fig. 1B). Several shorter peptides, ranging from 6 to 22 amino acids, also showed $100 \%$ homology to FKBP52. FKBP52 is a 52-kDa cellular protein, also known as an immunophilin (46), is ubiquitous, is phosphorylated, and localizes predominantly to the nucleus $(5,37,38)$, several properties that are shared with ssD-BP. The identity of ssD-BP as the cellular FKBP52 was tested in the following two sets of experiments. In the first set, supershift EMSA were performed using anti-FKBP52 antibody. The results are shown in Fig. 2. As can be seen, the AAV D-sequence probe (lane 1) formed a slowermigrating complex with WCE from HeLa cells (lane 2) and a faster-migrating complex with WCE from 293 cells (lane 3), consistent with our previously published reports $(40,42)$; the inclusion of anti-FKBP52 antibody in these assays resulted in a nearly complete supershift with HeLa (lane 4) and 293 (lane 5) WCEs, respectively. These supershifted complexes were not detected when anti- $\beta_{1}$ integrin antibody was used as an appropriate control (lanes 6 and 7). The AAV D-sequence probe did not form a complex with either anti-FKBP52 antibody (lane 8) or anti- $\beta_{1}$ integrin antibody (lane 9 ).

In the second set of experiments, WCEs from HeLa and 293 cells were immunoprecipitated with anti-FKBP52 antibody, and the supernatants and pellets, following resuspension, were used in EMSA. As can be seen in Fig. 2, prior immunoprecipitation with anti-FKBP52 antibody eliminated ssD-BP from WCEs from both HeLa and 293 cells (lanes 10 and 11), and it could be recovered from the pellets (lanes 12 and 13). Taken together, these results corroborate the notion that ssD-BP is FKBP52. However, it was crucial to document that (i) the FKBP52 protein is phosphorylated in vitro by EGFR-PTK, (ii) the FKBP52 protein binds to the AAV D $(-)$ sequence, and (iii) tyrosine-phosphorylated FKBP52, but not unphosphorylated FKBP52, inhibits AAV second-strand DNA synthesis. Each of these requirements was experimentally tested as follows.

FKBP52 can be phosphorylated at tyrosine residues by EGFR-PTK. Previous studies have shown that FKBP52 can be phosphorylated in vitro by CK II (29). Using in vitro phosphorylation assays, we wished to document whether purified FKBP52 could also be phosphorylated by EGFR-PTK, since ssD-BP is phosphorylated by EGFR-PTK (26). These assays were carried out as described in Materials and Methods. Because both CK II and EGFR-PTK are known to be autophosphorylated, assays were also carried out in the absence of FKBP52. The results are shown in Fig. 3. It is evident that FKBP52 is phosphorylated not only at serine or threonine residues (lane 2), as reported previously (29), but also at tyrosine residues (lane 4 ), consistent with our previous studies (26).

Phosphorylation of FKBP52 dramatically stimulates its interaction with the AAV D-sequence. It was of interest to determine whether the purified FKBP52 protein could bind to the AAV D $(-)$ sequence. The purified FKBP52 protein was used in EMSA with the AAV D(-) probe, with and without prior in vitro phosphorylation by CK II and EGFR-PTK as described above. The CK II and EGFR-PTK proteins were also used as appropriate controls. The results are shown in Fig. 


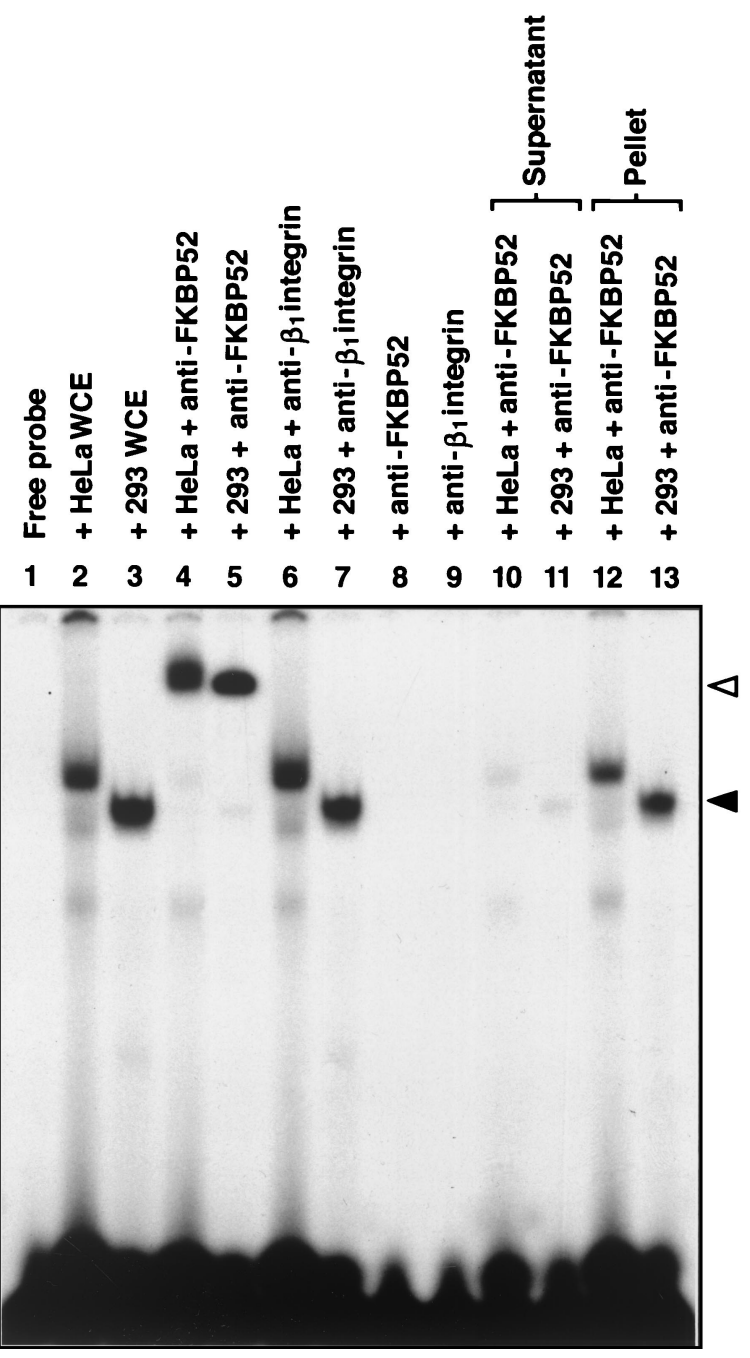

FIG. 2. Electrophoretic mobility supershift assays and immunoprecipitation of WCEs with anti-FKBP52 antibody. The AAV D-sequence probe (lane 1) was incubated with WCEs prepared from HeLa cells to yield a slower-migrating complex (lane 2; solid arrow) and with those from 293 cells to form a faster-migrating complex (lane 3; solid arrowhead). These complexes were supershifted by incubation with antiFKBP52 antibody with HeLa (lane 4; open arrow) and 293 (lane 5; open arrowhead) WCEs, respectively, but not with anti- $\beta_{1}$ integrin antibody (lanes 6 and 7). No complex formation occurred between the AAV D-sequence probe and either anti-FKBP52 antibody (lane 8) or anti- $\beta_{1}$ integrin antibody (lane 9). When WCEs from HeLa and 293 cells were immunoprecipitated with anti-FKBP52 antibody and supernatants and pellets, following resuspension, were used in EMSA, prior immunoprecipitation with anti-FKBP52 antibody eliminated ssD-BP from WCEs from both HeLa and 293 cells (lanes 10 and 11), and it could be recovered from the pellets (lanes 12 and 13).

4. It is evident that little binding of unphosphorylated FKBP52 to the D-sequence probe occurred (lane 2), whereas FKBP52 phosphorylated at serine or threonine residues by CK II (lane 3) formed a complex with the probe. CK II alone did not interact with the $\mathrm{D}(-)$ probe (lane 4). FKBP52 phosphorylated at tyrosine residues by EGFR-PTK (lane 5) formed two distinct complexes, whereas EGFR-PTK alone did not interact with the $\mathrm{D}(-)$ probe (lane 6$)$. There are 16 tyrosine residues in FKBP52, and it is possible that the faster-migrating complex in

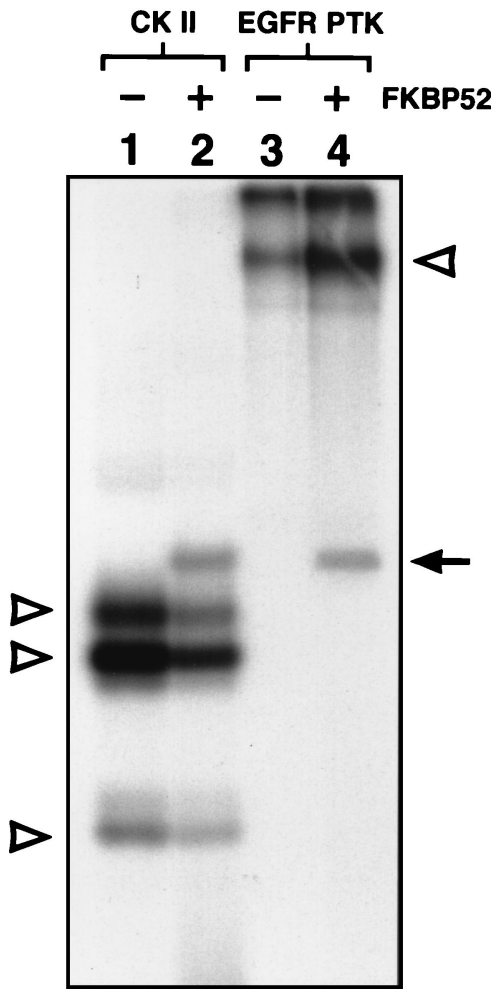

FIG. 3. In vitro phosphorylation of purified FKBP52 protein by CK II and EGFR-PTK. CK II was incubated in the absence (-; lane 1) or presence (+; lane 2) of $1 \mu \mathrm{g}$ of FKBP52. Similarly, EGFR-PTK was incubated in the absence (lane 3) or presence (lane 4) of FKBP52 as described in Materials and Methods. The arrow indicates the phosphorylated FKBP52 protein, and the arrowheads denote the autophosphorylated CK II and EGFR-PTK proteins.

lane 5 is the partially phosphorylated FKBP52. These results nonetheless corroborate the notion that the ssD-BP is FKBP52.

Only phosphorylated forms of FKBP52 inhibit AAV secondstrand DNA synthesis. We also wished to examine the effect of the unphosphorylated and/or phosphorylated FKBP52 on AAV second-strand DNA synthesis. The purified FKBP52 protein, with and without phosphorylation with CK II or EGFR-PTK, was used in in vitro DNA replication assays as described in Materials and Methods. As shown in Fig. 5, the radiolabeled AAV hairpin DNA template (lane 1) was readily converted into its duplex counterpart following second-strand DNA synthesis by the Klenow enzyme (lane 2). Prior incubation with the unphosphorylated FKBP52 protein had no effect (lane 3), and CK II-phosphorylated FKBP52 inhibited secondstrand DNA synthesis by $\approx 40 \%$ (lane 4 ) as determined by densitometric scanning of the autoradiographs. CK II in the absence of FKBP52 had no effect (lane 5). FKBP52 phosphorylated by EGFR-PTK inhibited viral second-strand DNA synthesis by $>90 \%$ (lane 6), and EGFR-PTK alone had no effect (lane 7). Thus, although the assay utilized here is somewhat artificial, it documents the fact that the phosphorylated forms, but not the unphosphorylated form, of FKBP52 inhibit viral second-strand DNA synthesis.

Deliberate overexpression of FKBP52 in established cell lines leads to a significant increase in $\mathrm{AAV}$-mediated trans- 


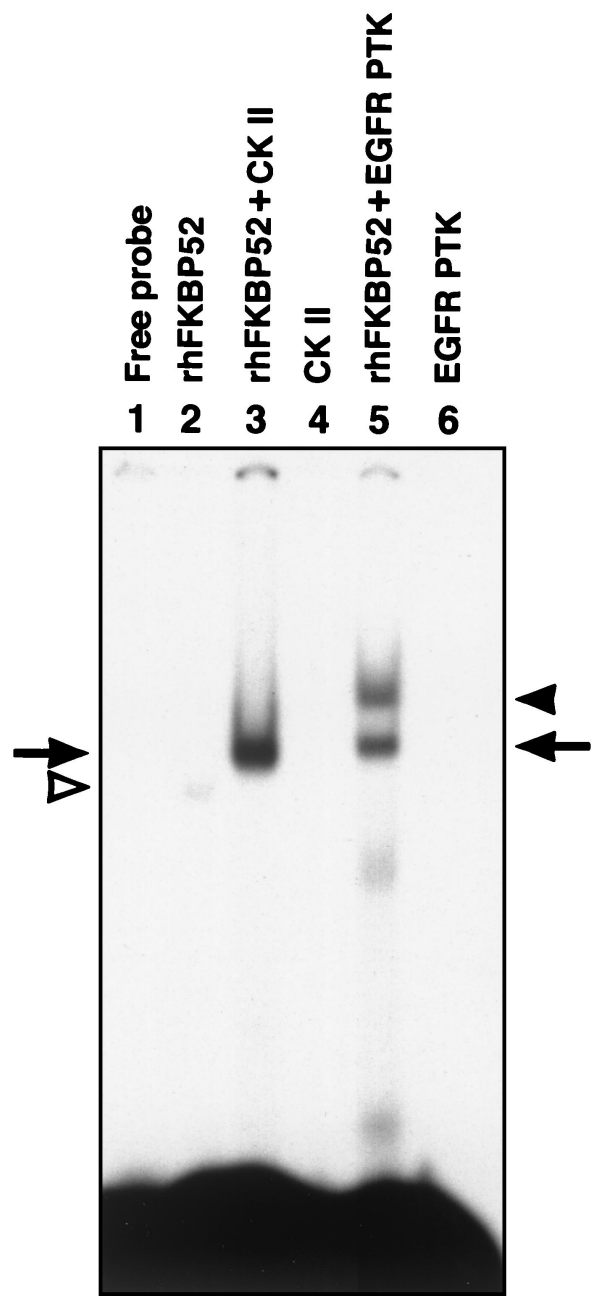

FIG. 4. Electrophoretic mobility shift assays for the AAV D(-) sequence (lane 1) interaction with human FKBP52 purified from bacterial cells without (lane 2) and with prior in vitro phosphorylation with CK II (lane 3) and EGFR-PTK (lane 5), respectively. These assays were performed as described in Materials and Methods. No interaction between the probe and CK II alone (lane 4) or EGFR-PTK alone (lane 6) was observed. Complexes presumed to contain the phosphorylated forms of the FKBP52 protein are denoted by the solid arrows and arrowhead, and the unphosphorylated form is denoted by the open arrowhead.

gene expression. In order to examine the effect of the FKBP52 protein on $\mathrm{AAV}$-mediated transgene expression in vivo, we also generated a eukaryotic expression plasmid containing the human FKBP52 gene driven by the CMV promoter. Human HeLa and 293 cells and murine NIH 3T3 cells were stably transfected with this plasmid, and the WCEs prepared were analyzed to detect human FKBP52 on Western blots using anti-human FKBP52 antibody as described in Materials and Methods. The results are shown in Fig. 6. Densitometric scanning of lumigraphs revealed $\approx 2$-fold overexpression of the human FKBP52 in HeLa and 293 cells. In NIH 3 T3 cells, the level of expression of the human FKBP52 was similar to those in mock-transfected 293 and HeLa cells. WCEs prepared from each cell type as well as cells stably transfected with the human FKBP52 expression plasmid were also used in EMSA with the

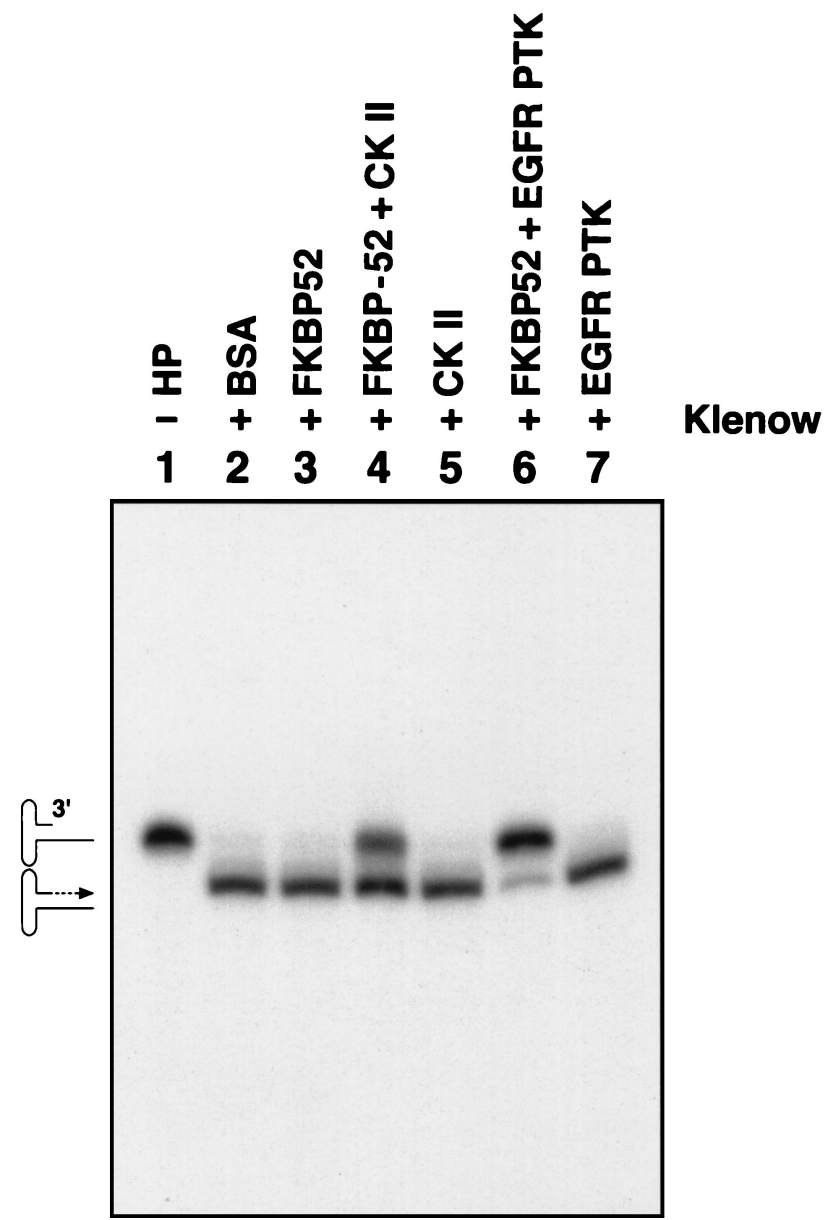

FIG. 5. In vitro replication assays for the effects of the purified FKBP52 protein, with and without phosphorylation by CK II or EGFR-PTK, on AAV second-strand DNA synthesis. These assays were carried out as described in Materials and Methods. The radiolabeled AAV hairpin (HP) DNA template (lane 1) (shown schematically as the upper figure on the left) was readily converted into its duplex counterpart (shown schematically as the lower figure on the left) following second-strand DNA synthesis by the Klenow enzyme (lane 2). Prior incubation with the dephosphorylated FKBP52 protein had no effect (lane 3), while CK II-phosphorylated FKBP52 inhibited secondstrand DNA synthesis by $\approx 40 \%$ (lane 4 ). CK II in the absence of FKBP52 had no effect (lane 5). FKBP52 phosphorylated by EGFRPTK inhibited viral second-strand DNA synthesis by $>90 \%$ (lane 6), and EGFR-PTK alone had no effect (lane 7). BSA, bovine serum albumin; +, present; -, absent.

AAV D $(-)$ probe, and the results are shown in Fig. 7. It is evident that in both NIH 3T3 and HeLa cells, deliberate overexpression of FKBP52 led to a significant reduction of tyrosine-phosphorylated FKBP52, the underlying mechanism of which is unclear. No effect was observed in 293 cells, since the FKBP52 present in these cells is phosphorylated predominantly at serine or threonine residues.

Since FKBP52, dephosphorylated at tyrosine residues, would be expected to be less inhibitory to AAV second-strand DNA synthesis, we wished to determine whether NIH 3T3 and HeLa cells, stably transfected with the FKBP52 expression plasmid, would allow an increase in AAV-mediated transgene expression. Mock-transfected or FKBP52 expression plasmid- 


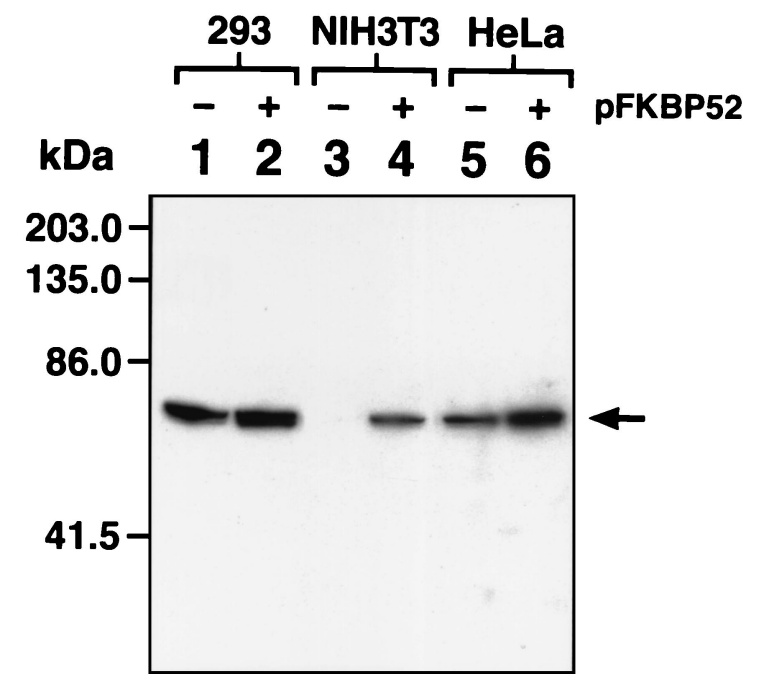

FIG. 6. Western blot analysis for expression of human FKBP52 in human 293 and HeLa cells and murine NIH 3T3 cells. Mock-transfected cells (lanes 1,3, and 5) and cells stably transfected with a human FKBP52 expression plasmid (lanes 2, 4, and 6) were analyzed using human anti-FKBP52 antibody as described in Materials and Methods. The arrow indicates the $52-\mathrm{kDa}$ human FKBP52 protein. +, present; - , absent.

transfected HeLa, 293, and NIH 3 T3 cells were either mock infected or infected with a recombinant $\mathrm{AAV}$-lac $Z$ vector under identical conditions. Transgene expression was evaluated $48 \mathrm{~h}$ postinfection. The results are shown in Fig. 8. It is evident that in both HeLa and NIH 3 T3 cells, with reduced levels of tyrosine-phosphorylated FKBP52, the AAV-mediated transduction efficiency was increased approximately 2- and 10-fold, respectively. However, since FKBP52 in 293 cells is present in predominantly dephosphorylated form (Fig. 7), FKBP52 overexpression did not significantly increase the AAV transduction efficiency in these cells. These studies document that there is a strong correlation between the tyrosine-phosphorylation status of the cellular FKBP52 protein and AAV transduction efficiency.

\section{DISCUSSION}

Although AAV has gained attention as a useful alternative to the more commonly used retrovirus- and adenovirus-based vectors for human gene therapy, recent studies from our laboratory and others have suggested that there are at least three major obstacles that limit high-efficiency transduction by AAV vectors in certain cell types. These include the lack of expression of the cellular receptor and coreceptor for AAV infection $(41,49,50)$, impaired intracellular trafficking of the virus into the nucleus $(13,14)$, and the inability of AAV to undergo viral second-strand DNA synthesis to yield the transcriptionally active double-stranded template $(8,9)$. For example, it has become abundantly clear that AAV infection requires the cell surface expression of heparan sulfate proteoglycan as a receptor for viral binding (50) and fibroblast growth factor receptor 1 and/or $\alpha \mathrm{V} \beta 5$ integrin as a coreceptor for viral entry $(41,49)$. Second, endosomal processing has recently been suggested to lead to efficient intracellular trafficking of AAV into the nu-

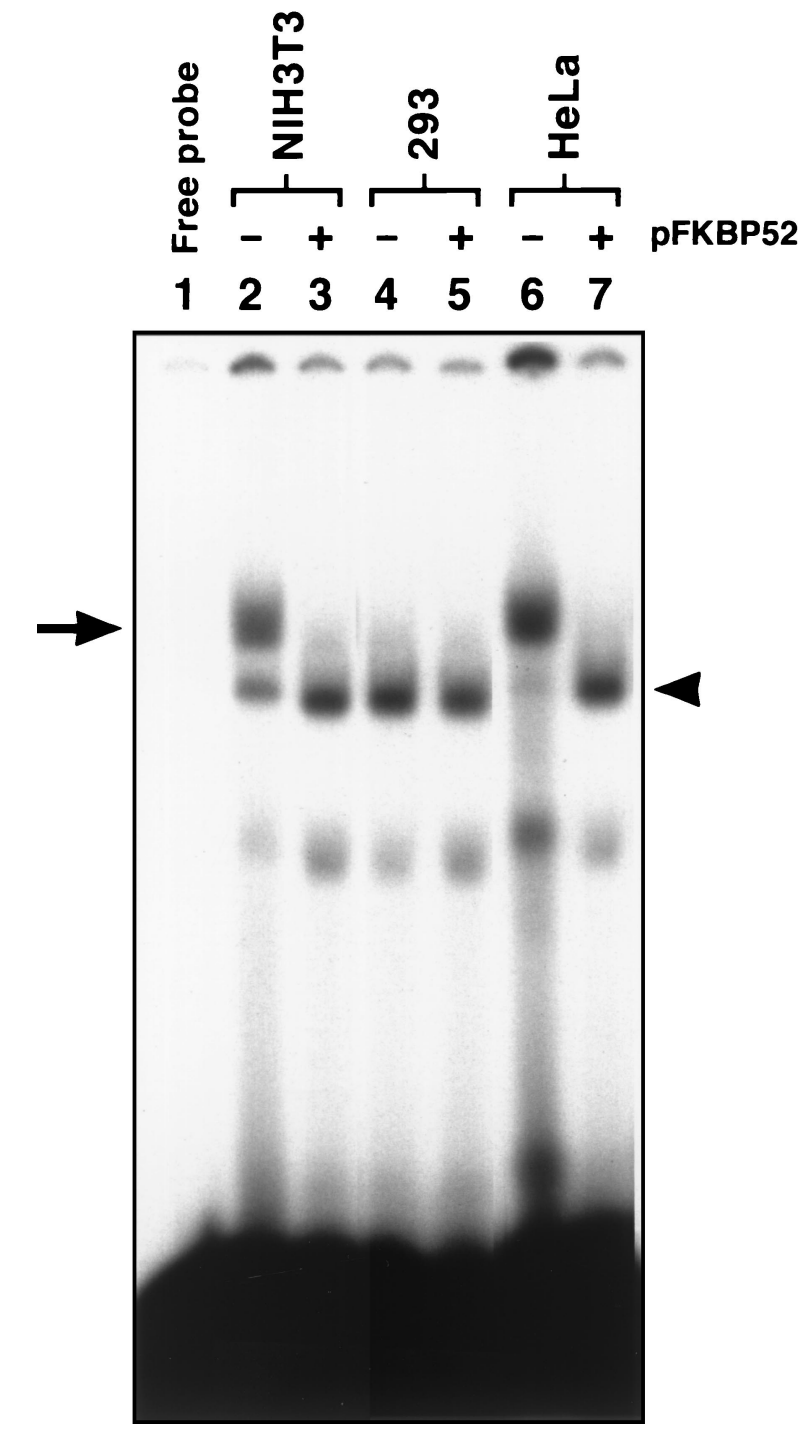

FIG. 7. Electrophoretic mobility shift assays for the AAV D(-) sequence interaction with FKBP52 in mock-transfected NIH 3T3, 293, and HeLa cells (lanes 2, 4, and 6) or cells stably transfected with the human FKBP52 expression plasmid (lanes 3, 5, and 7). These assays were carried out as described in the legend to Fig. 4. The tyrosinephosphorylated form of the FKBP52 protein is denoted by the arrow, and the serine- or threonine-phosphorylated form is denoted by the arrowhead. +, present; -, absent.

cleus $(6,7)$. Third, we have documented that a cellular protein, designated ssD-BP, the identity of which has thus far remained unknown, plays an important role in viral second-strand DNA synthesis $(25,26,40,42)$.

In the present studies, we purified the ssD-BP and identified it as a $52-\mathrm{kDa}$ cellular protein, FKBP52, that binds the immunosuppressant drug FK506. The human FKBP52, also known as an immunophilin, is ubiquitous, is phosphorylated, and localizes predominantly to the nucleus, properties that are shared with ssD-BP (40-42). Using the purified recombinant protein, we documented that (i) FKBP52 can be phosphorylated in vitro at both serine and threonine residues by CK II and at tyrosine residues by EGFR-PTK; (ii) phosphorylated 

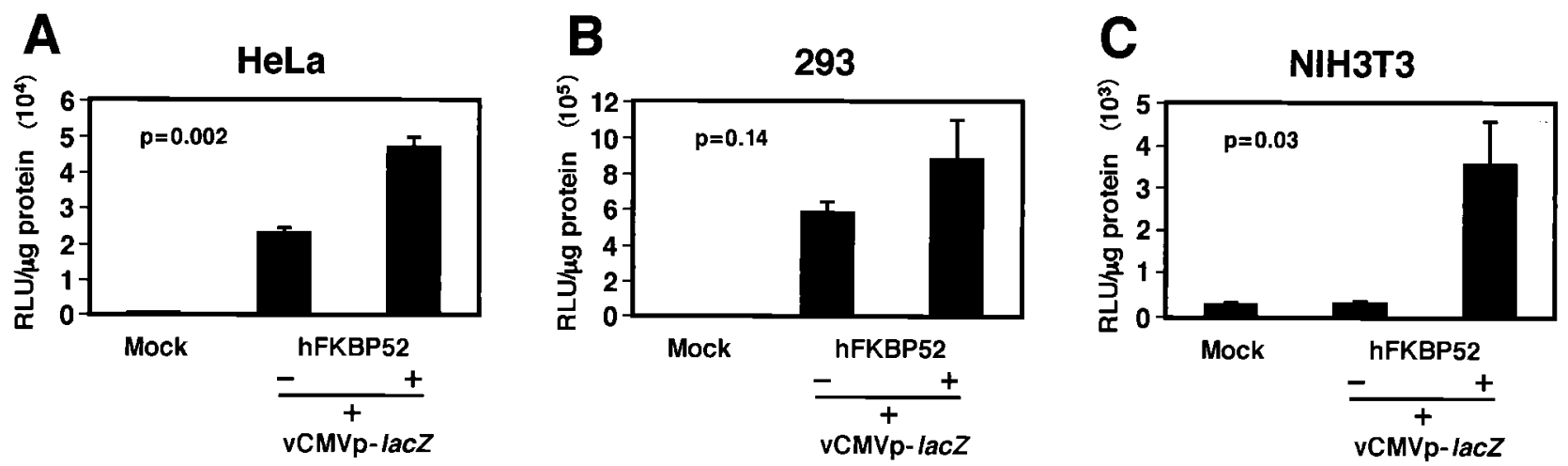

FIG. 8. Comparative analyses of AAV-mediated transduction efficiency in cells overexpressing the FKBP52 protein. Mock-transfected or FKBP52 expression plasmid-transfected HeLa (A), 293 (B), and NIH 3T3 (C) cells were either mock infected or infected with a recombinant $\mathrm{AAV}-l a c Z$ vector under identical conditions. Transgene expression was evaluated $48 \mathrm{~h}$ postinfection as described in Materials and Methods. These data represent results from experiments performed in triplicate with the standard error of the mean. Statistical differences were determined by using an unpaired Student $t$ test. +, present; -, absent.

forms, but not the unphosphorylated form, of FKBP52 interact efficiently in vitro with the AAV single-stranded D sequence; (iii) FKBP52 phosphorylated at tyrosine residues inhibits AAV second-strand DNA synthesis more efficiently than that phosphorylated at serine or threonine residues, whereas unphosphorylated FKBP52 has no effect; and (iv) deliberate overexpression of FKBP52 effectively reduces tyrosine phosphorylation of the protein, which leads to more efficient AAV-mediated transgene expression in human and murine established cell lines in vitro. In view of these data, we have revised our previously published model of AAV DNA second-strand synthesis and transgene expression $(25,26)$, as shown in Fig. 9. In the revised model, cellular FKBP52, phosphorylated either at tyrosine residues by EGFR-PTK or at serine or threonine residues (previously assumed to be the unphosphorylated form of ssD-BP [27]) by an unknown cellular serine or threonine protein tyrosine kinase, interacts with the $\mathrm{D}(-)$ sequence in the AAV ITR and inhibits viral second-strand DNA synthesis. Coinfection with adenovirus, expression of adenovirus E4orf6 protein, or treatment with inhibitors of tyrosine and serine or threonine kinase inhibitors leads to dephosphorylation of FKBP52, which can no longer bind to the $\mathrm{D}(-)$ sequence, thereby allowing viral second-strand DNA synthesis and, consequently, efficient transgene expression.

In our previously published studies with HeLa cells (26), we did not see any effect of staurosporine, a serine or threonine kinase inhibitor, on AAV-mediated transgene expression. Since FKBP52 present in HeLa cells is phosphorylated predominantly at tyrosine residues, that was not unexpected. However, since KB cells contain FKBP52 phosphorylated at both tyrosine and serine or threonine residues (40), we have examined the effects of tyrphostin 1 and staurosporine on $\mathrm{AAV}$-mediated lac $\mathrm{Z}$ transgene expression in $\mathrm{KB}$ cells. These results document that treatment with tyrphostin 1 or staurosporine leads to a significant increase in AAV-mediated transgene expression in $\mathrm{KB}$ cells (data not shown). Thus, the identification of the putative cellular serine or threonine kinase which catalyzes phosphorylation of FKBP52 remains a high priority.
In preliminary experiments, we have tentatively identified a cellular tyrosine phosphatase, designated T-cell protein tyrosine phosphatase (TC-PTP) $(24,56)$, which catalyzes dephosphorylation of FKBP52, since stable transfection of a TCPTP expression plasmid into HeLa cells led to a significant

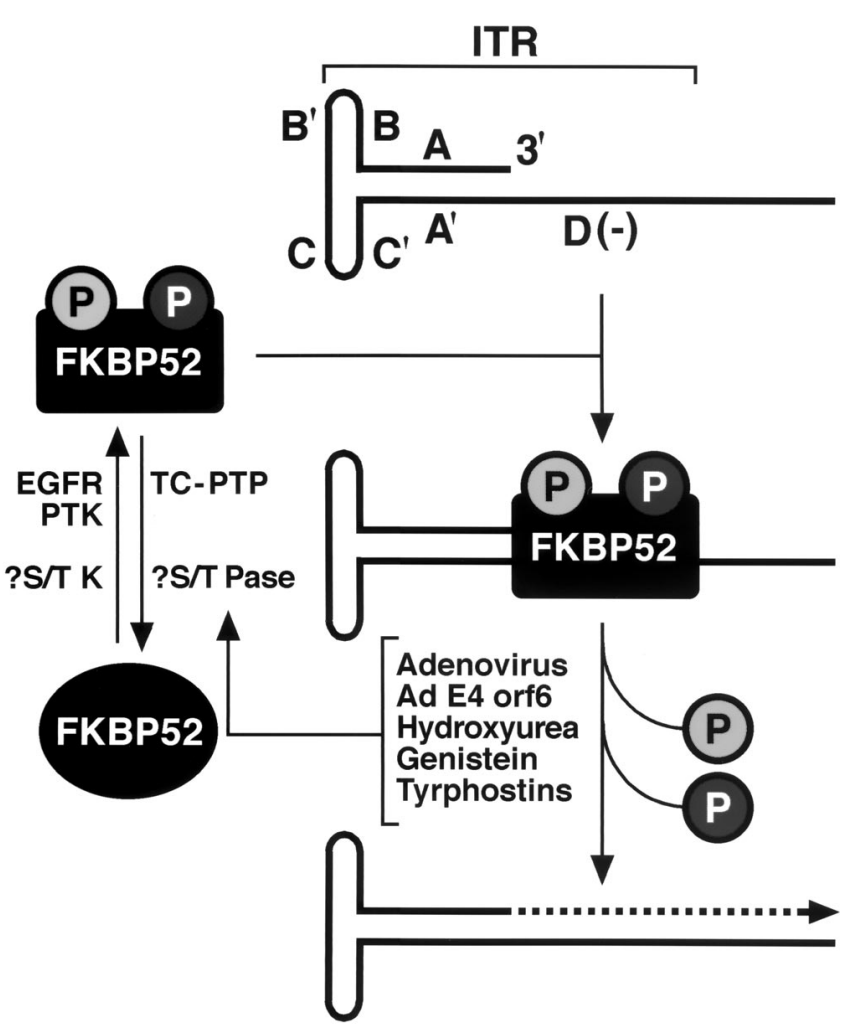

FIG. 9. Revised model for the role of the cellular FKBP52 protein in AAV second-strand DNA synthesis. See the text for details. Shaded circles represent phosphorylated serine (or threonine) and tyrosine residues. The broken-lined arrow indicates the viral second-strand DNA synthesis. 
increase in AAV-mediated transgene expression (K. Qing, W. Li, M. Tan, M. C. Yoder, and A. Srivastava, unpublished data). It is obvious, therefore, that further characterization of the cellular serine or threonine and tyrosine phosphatases would be instrumental in achieving optimal transduction by AAV vectors.

It is also obvious that FKBP52 plays an important role in the host cell. Indeed, a number of cellular processes have been identified in which FKBP52 is involved. For example, FKBP52 has been shown to be a chaperone protein, since it can bind to heat shock protein, HSP90, and form a complex, suggesting a role of FKBP52 in protein folding and delivery (5). Interestingly, however, FKBP52 has been documented to interact with HSP90 only when dephosphorylated at serine or threonine residues, and this complex has been shown to mediate cytoplasmic transport of a number of cellular and viral proteins to the nucleus (37-39). Whether FKBP52 phosphorylated at tyrosine residues forms a complex with HSP90 remains unknown, and whether the FKBP52-HSP90 complex is also involved in AAV trafficking to the nucleus remains to be determined. Our ongoing studies of site-directed mutagenesis of individual serine, threonine, and tyrosine residues in FKBP52 and the development of FKBP52 knockout cell lines and mice will allow us to gain further knowledge of the role of FKBP52, not only in the host cell, but also in the AAV life cycle in general and AAV-mediated gene transfer in particular. Thus, the elucidation of these relationships will likely have important implications for the successful use of AAV vectors in human gene therapy.

\section{ACKNOWLEDGMENTS}

We thank Etienne-Emile Baulieu for his kind gift of the rabbit FKBP52 cDNA expression plasmid.

This research was supported in part by Public Health Service grants (HL-53586, HL-58881, and DK-49218; Centers of Excellence in Molecular Hematology) from the National Institutes of Health and a grant from the Phi Beta Psi sorority.

\section{REFERENCES}

1. Berns, K. I., and C. Giraud. 1996. Biology of adeno-associated virus. Curr. Top. Microbiol. Immunol. 218:1-23.

2. Carter, B. J., and T. R. Flotte. 1996. Development of adeno-associated virus vectors for gene therapy of cystic fibrosis. Curr. Top. Microbiol. Immunol. 218:119-144.

3. Chatterjee, S., D. Lu, G. Podsakoff, and K. K. Wong, Jr. 1995. Strategies for efficient gene transfer into hematopoietic cells: the use of adeno-associated virus vectors in gene therapy. Ann. N. Y. Acad. Sci. 770:79-90.

4. Cybulsky, A. V., P. R. Goodyer, and A. J. McTavish. 1994. Epidermal growth factor receptor activation in developing rat kidney. Am. J. Physiol. 267:F428F436.

5. Czar, M. J., R. H. Lyons, M. J. Welsh, J.-M. Renoir, and W. B. Pratt. 1995 Evidence that the FK506-binding protein 56 is required for trafficking of the glucocorticoid receptor from the cytoplasm to the nucleus. Mol. Endocrinol. 9:1549-1560.

6. Douar, A.-M., K. Poulard, D. Stockholm, and O. Danos. 2001. Intracellular trafficking of adeno-associated virus vectors: routing to the late endosomal compartment and proteasome degradation. J. Virol. 75:1824-1833.

7. Duan, D., Z. Yan, J. Yang, and J. F. Engelhardt. 2000. Endosomal processing limits gene transfer to polarized airway epithelia by adeno-associated virus. J. Clin. Investig. 105:1573-1587.

8. Ferrari, F. K., T. Samulski, T. Shenk, and R. J. Samulski. 1996. Secondstrand synthesis is a rate-limiting step for efficient transduction by recombinant adeno-associated virus vectors. J. Virol. 70:3227-3234.

9. Fisher, K. J., G.-P. Gao, M. D. Weitzman, R. DeMatteo, J. F. Burda, and J. M. Wilson. 1996. Transduction with recombinant adeno-associated virus for gene therapy is limited by leading-strand synthesis. J. Virol. 70:520-532.

10. Flores, E. R., and P. F. Lambert. 1997. Evidence for a switch in the mode of human papillomavirus type 16 DNA replication during the viral life cycle. J. Virol. 71:7167-7179.
11. Flotte, T. R., B. J. Carter, C. K. Conrad, W. B. Guggino, T. C. Reynolds, B. Rosenstein, G. Taylor, S. Walden, and R. Wetzel. 1996. A phase I study of an adeno-associated virus-CFTR gene vector in adult CF patients with mild lung disease. Hum. Gene Ther. 7:1145-1159.

12. Flotte, T. R., S. A. Afione, C. Conrad, S. A. McGrath, R. Solow, H. Oka, P. L. Zeitlin, B. Guggino, and B. J. Carter. 1993. Stable in vivo expression of the cystic fibrosis transmembrane conductance regulator with an adeno-associated virus vector. Proc. Natl. Acad. Sci. USA 90:10613-10617.

13. Hansen, J., K. Y. Qing, H.-J. Kwon, C. Mah, and A. Srivastava. 2000. Impaired intracellular trafficking of adeno-associated virus type 2 vectors limits efficient transduction of murine fibroblasts. J. Virol. 74:992-997.

14. Hansen, J., K. Y. Qing, and A. Srivastava. 2001. Adeno-associated virus type 2-mediated gene transfer: altered endocytic processing enhances transduction efficiency in murine fibroblasts. J. Virol. 75:4080-4090.

15. Johansson, E., K. Hjortsberg, and L. Thelander. 1998. Two YY-1-binding proximal elements regulate the promoter strength of the TATA-less mouse ribonucleotide reductase gene. J. Biol. Chem. 273:29816-29821.

16. Kaplitt, M. G., P. Leone, R. J. Samulski, X. Xiao, D. W. Pfaff, K. L. O’Malley, and M. J. During. 1994. Long-term gene expression and phenotypic correction using adeno-associated virus vectors in the mammalian brain. Nat. Genet. 8:148-153.

17. Kaplitt, M. G., X. Xiao, R. J. Samulski, J. Li, K. Ojamaa, I. L. Klein, H. Makimura, M. J. Kaplitt, R. K. Strumpf, and E. B. Diethrich. 1996. Longterm gene transfer in porcine myocardium after coronary infusion of an adeno-associated virus vector. Ann. Thorac. Surg. 62:1669-1676.

18. Kay, M. A., C. S. Manno, M. V. Ragni, P. J. Larson, L. B. Couto, A. McClelland, B. Glader, A. J. Chew, S. J. Tai, R. W. Herzog, V. Arruda, F. Johnson, C. Scallan, E. Skarsgard, A. W. Flake, and K. A. High. 2000. Evidence for gene transfer and expression of factor IX in hemophilia B patients treated with an AAV vector. Nat. Genet. 28:257-261.

19. Kessler, P. D., G. M. Podsakoff, X. Chen, S. A. McQuiston, P. C. Colosi, L. A. Matelis, G. J. Kurtzman, and B. J. Byrne. 1996. Gene delivery to skeletal muscle results in sustained expression and systemic delivery of a therapeutic protein. Proc. Natl. Acad. Sci. USA 93:14082-14087.

20. Knössl, M., R. Löwer, and J. Löwer. 1999. Expression of the human endogenous retrovirus HTDV/HERV-K is enhanced by cellular transcription factor YY1. J. Virol. 73:1254-1261.

21. Koeberl, D. D., I. E. Alexander, C. L. Halbert, D. W. Russell, and A. D. Miller. 1997. Persistent expression of human clotting factor IX from mouse liver after intravenous injection of adeno-associated virus vectors. Proc. Natl. Acad. Sci. USA 94:1426-1431.

22. Kotin, R. M., J. C. Menninger, D. C. Ward, and K. I. Berns. 1991. Mapping and direct visualization of a region-specific viral DNA integration site on chromosome 19q13-qter. Genomics 10:831-834.

23. Kotin, R. M., M. Siniscalco, R. J. Samulski, X. D. Zhu, L. A. Hunter, C. A Laughlin, S. K. McLaughlin, N. Muzyczka, M. Rocchi, and K. I. Berns. 1990. Site-specific integration by adeno-associated virus. Proc. Natl. Acad. Sci. USA 87:2211-2215.

24. Lorenzen, J. A., C. Y. Dadabay, and E. H. Fischer. 1995. COOH-terminal sequence motifs target the T cell protein tyrosine phosphatase to the ER and nucleus. J. Biol. Chem. 131:631-643.

25. Mah, C., K. Y. Qing, J. Hansen, B. Khuntrirat, M. C. Yoder, and A. Srivastava. 1999. Gene transfer with adeno-associated virus 2 vectors: the growth factor receptor connection. Gene Ther. Mol. Biol. 3:57-65.

26. Mah, C., K. Y. Qing, B. Khuntrirat, S. Ponnazhagan, X.-S. Wang, D. M. Kube, M. C. Yoder, and A. Srivastava. 1998. Adeno-associated virus 2-mediated gene transfer: role of epidermal growth factor receptor protein tyrosine kinase in transgene expression. J. Virol. 72:9835-9841.

27. McCown, T. J., X. Xiao, J. Li, G. R. Breese, and R. J. Samulski. 1996. Differential and persistent expression patterns of CNS gene transfer by an adeno-associated virus (AAV) vector. Brain Res. 713:99-107.

28. McElhinny, J. A., S. A. Trushin, G. D. Bren, N. Chester, and C. V. Paya. 1996. Casein kinase II phosphorylates Iк B $\alpha$ at S-283, S-289, and T-291 and is required for its degradation. Mol. Cell. Biol. 16:899-906.

29. Miyata, Y., B. Chambraud, C. Radanyi, J. Leclerc, M.-C. Lebeau, K.-M. Renoir, R. Shirai, M.-G. Catelli, I. Yahara, and E.-E. Baulieu. 1997. Phosphorylation of the immunosuppressant FK506-binding protein FKBP52 by casein kinase II: regulation of HSP90-binding activity of FKBP52. Proc. Natl. Acad. Sci. USA 94:14500-14505.

30. Muller, M. T. 1987. Binding of herpes simplex virus immediate-early gene product ICP4 to its own transcription start site. J. Virol. 61:858-865.

31. Muzyczka, N. 1992. Use of adeno-associated virus as a general transduction vector for mammalian cells. Curr. Top. Microbiol. Immunol. 158:97-129.

32. Nathwani, A. C., H. Hanawa, J. Vandergriff, P. Kelly, E. F. Vanin, and A. W. Nienhuis. 2000. Efficient gene transfer into human cord blood CD34 ${ }^{+}$cells and the $\mathrm{CD} 34^{+} \mathrm{CD} 38^{-}$subset using highly purified recombinant adenoassociated viral vector preparations that are free of helper virus and wildtype AAV. Gene Ther. 7:183-195.

33. Ping, P., Q. Yang, and H. K. Hammond. 1996. Altered beta-adrenergic receptor signaling in heart failure, in vivo gene transfer via adeno and adeno-associated virus. Microcirculation 3:225-228.

34. Ponnazhagan, S., P. Mukherjee, X.-S. Wang, K. Y. Qing, D. M. Kube, C. 
Mah, C. Kurpad, M. C. Yoder, E. F. Srour, and A. Srivastava. 1997. Adenoassociated virus type 2-mediated transduction of primary human bone marrow-derived $\mathrm{CD}_{3}{ }^{+}$hematopoietic progenitor cells: donor variation and correlation of transgene expression with cellular differentiation. J. Virol. 71:8262-8267.

35. Ponnazhagan, S., P. Mukherjee, M. C. Yoder, X.-S. Wang, S. Z. Zhou, J. Kaplan, S. Wadsworth, and A. Srivastava. 1997. Adeno-associated virus 2-mediated gene transfer in vivo: organ-tropism and expression of transduced sequences in mice. Gene 190:203-210.

36. Ponnazhagan, S., M. C. Yoder, and A. Srivastava. 1997. Adeno-associated virus type 2-mediated transduction of murine hematopoietic cells with longterm repopulating ability and sustained expression of a human globin gene in vivo. J. Virol. 71:3098-3104.

37. Pratt, W. B. 1998. The hsp90-based chaperone system: involvement in signal transduction from a variety of hormone and growth factor receptors. Proc. Soc. Exp. Biol. Med. 217:420-434.

38. Pratt, W. B., and D. O. Toft. 1997. Steroid receptor interactions with heat shock protein and immunophilin chaperones. Endocr. Rev. 18:306-360.

39. Pratt, W. B., A. M. Silverstein, and M. D. Galigniana. 1999. A model for the cytoplasmic trafficking of signaling proteins involving the hsp90-binding im-

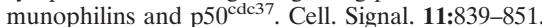

40. Qing, K. Y., B. Khuntrirat, C. Mah, D. M. Kube, X.-S. Wang, S. Ponnazhagan, S. Z. Zhou, V. J. Dwarki, M. C. Yoder, and A. Srivastava. 1998. Adeno-associated virus type 2-mediated gene transfer: correlation of tyrosine phosphorylation of the cellular single-stranded D sequence-binding protein with transgene expression in human cells in vitro and murine tissues in vivo. J. Virol. 72:1593-1599.

41. Qing, K. Y., C. Mah, J. Hansen, S. Z. Zhou, V. J. Dwarki, and A. Srivastava 1999. Human fibroblast growth factor receptor 1 is a co-receptor for infection by adeno-associated virus 2. Nat. Med. 5:71-77.

42. Qing, K. Y., X.-S. Wang, D. M. Kube, S. Ponnazhagan, A. Bajpai, and A. Srivastava. 1997. Role of tyrosine phosphorylation of a cellular protein in adeno-associated virus 2-mediated transgene expression. Proc. Natl. Acad. Sci. USA 94:10879-10884

43. Russo, G. L., M. T. Vandenberg, I. J. Yu, Y. S. Bae, B. R. Franza, Jr., and D. R. Marshak. 1992. Casein kinase II phosphorylates p34cdc2 kinase in G1 phase of the HeLa cell division cycle. J. Biol. Chem. 267:20317-20325.

44. Sambrook, J., E. F. Fritsch, and T. Maniatis. 1989. Molecular cloning: a laboratory manual, 2nd ed. Cold Spring Harbor Laboratory Press, Cold Spring Harbor, N.Y.

45. Samulski, R. J., X. Zhu, X. Xiao, J. D. Brook, D. E. Houseman, N. Epstein, and L. A. Hunter. 1991. Targeted integration of adeno-associated virus
(AAV) into human chromosome 19. EMBO J. 10:3941-3950.

46. Schreiber, S. L. 1991. Chemistry and biology of the immunophilins and their immuno-suppressive ligands. Science 251:283-287.

47. Snyder, R. O., C. H. Miao, G. A. Patijn, S. K. Spratt, O. Danos, D. Nagy, A. M. Gown, B. Winther, L. Meuse, L. K. Cohen, A. R. Thompson, and M. A Kay. 1997. Persistent and therapeutic concentrations of human factor IX in mice after hepatic gene transfer of recombinant AAV vectors. Nat. Genet. 16:270-276.

48. Srivastava, A., X.-S. Wang, S. Ponnazhagan, S. Z. Zhou, and M. C. Yoder. 1996. Adeno-associated virus 2-mediated transduction and erythroid lineagespecific expression in human hematopoietic progenitor cells. Curr. Top. Microbiol. Immunol. 218:93-117.

49. Summerford, C., J. S. Bartlett, and R. J. Samulski. 1999. $\alpha$ Vß5 integrin: co-receptor for adeno-associated virus 2 infection. Nat. Med. 5:78-82.

50. Summerford, C., and R. J. Samulski. 1998. Membrane-associated heparan sulfate proteoglycan is a receptor for adeno-associated virus type 2 virions. J. Virol. 72:1438-1445.

51. Walsh, C. E., J. M. Liu, J. L. Miller, A. W. Nienhuis, and R. J. Samulski. 1993. Gene therapy for human hemoglobinopathies. Proc. Soc. Exp. Biol. Med. 204:289-300

52. Wang, X.-S., S. Ponnazhagan, and A. Srivastava. 1996. Rescue and replication of adeno-associated virus type 2 as well as vector DNA sequences from recombinant plasmids containing deletions in the viral inverted terminal repeats: selective encapsidation of viral genomes in progeny virions. J. Virol. 70:1668-1677.

53. Wang, X.-S., K. Y. Qing, S. Ponnazhagan, and A. Srivastava. 1997. Adenoassociated virus type 2 DNA replication in vivo: mutation analyses of the D sequence in viral inverted terminal repeats. J. Virol. 71:3077-3082.

54. Weber, W., P. J. Bertics, and G. N. Gill. 1984. Immunoaffinity purification of the epidermal growth factor receptor. Stoichiometry of binding and kinetics of self-phosphorylation. J. Biol. Chem. 259:14631-14636.

55. Xiao, X., J. Li, and R. J. Samulski. 1996. Efficient long-term gene transfer into muscle tissue of immunocompetent mice by adeno-associated virus vector. J. Virol. 70:8098-8108.

56. You-Ten, K. E., E. Muise, A. Itie, E. Michaliszyn, J. Wagner, S. Jothy, W. S. Lapp, and M. L. Tremblay. 1997. Impaired bone marrow microenvironmen and immune function in $\mathrm{T}$ cell protein tyrosine phosphatase-deficient mice. J. Exp. Med. 186:683-693.

57. Zhou, S. Z., Q. Li, G. Stamatoyannopoulos, and A. Srivastava. 1996. Adenoassociated virus 2-mediated transduction and erythroid cell-specific expression of a human $\beta$-globin gene. Gene Ther. 3:223-229. 